\title{
CORNEAL ENDOTHELIAL SPECULAR MICROSCOPY FOLLOWING FEMTOSECOND ASSISTED INTACS IMPLANTATION FOR KERATOCONUS
}

\author{
By
Anas Ali Abd El-Rahim Ali, Hassan Abd El-Wahab Aly and Abd El- Ghany Ibrahim Abd El-Ghany

Department of Ophthalmology, Faculty of Medicine, Al-Azhar University

Corresponding author: Anas Ali Abd El-Rahim Ali, E-mail: anasali6095@gmail.com

\begin{abstract}
Background: Keratoconus is an idiopathic, noninflammatory, ectatic corneal disease that causes progressive vision loss. Although the disease is bilateral, its effects are usually asymmetric. It causes paraxial stromal thinning and weakening, leading to corneal surface distortion. Vision loss in keratoconus is caused primarily by irregular astigmatism and myopia and secondarily by corneal scarring.

Objective: To study the effect and safety of Femtosecond assisted implantation of INTACs on corneal endothelium using specular microscopy.

Patients and methods: This was a prospective comparative study conducted on 20 eyes attended the outpatient clinic of the Ophthalmology Department at Al-Azhar University Hospital (Cairo) from October 2018 to October 2029 with Keratoconus who had implantation of intracorneal ring segments (INTACS). The effect and safety of femtosecond assisted implantation of INTACs on corneal endothelium using specular microscopy were studied.

Results: Regarding preoperative ophthalmic data, the mean preoperative intraocular pressure (IOP) was $(17.5 \pm 2.3) \mathrm{mmHg}$, the mean preoperative uncorrected visual acuity (UCVA) was $(0.17 \pm 0.1)$, and the mean preoperative best corrected visual acuity $(\mathrm{BCVA})$ was $(0.5 \pm 0.17)$. Regarding preoperative corneal topography data, the mean preoperative spherical equivalent was $-5.94 \pm 3.2 \mathrm{D}$. The mean preoperative cylinder was $(-3.5 \pm 1.68) \mathrm{D}$, and the mean preoperative topographic $\mathrm{K}$ values was $(48.3 \pm 3.9) \mathrm{D}$. Regarding preoperative specular microscopy data, the mean preoperative endothelial cell number was $2822.5 \pm 321.9$. The mean preoperative coefficient of variation was $29.2 \pm 4$, and the mean preoperative percentage hexagonal cell count was $54.6 \pm 7.7 \%$. There were significant increase in post-operative best corrected visual acuity (BCVA), and best corrected visual acuity (BCVA) assessments in keratoconus eyes ( $p<0.01$ respectively). By using ROC-curve analysis, femtosecond assisted implantation of implantation of intracorneal ring segments (INTACS) predicted endothelial cell number improvement, with fair $(72 \%)$ accuracy, sensitivity $=40 \%$ and specificity $=95 \%(\mathrm{p}<0.01)$.
\end{abstract}

Conclusion: The intrastromal ring was a stent designed to alter the corneal curvature and reduce refractive errors resulting from irregularities of corneal ectasia. The ring may improve the effect of optical correction with glasses or contact lenses.

Keywords: Corneal Endothelial, Specular Microscopy, Femtosecond, INTACS, Keratoconus. 


\section{INTRODUCTION}

Keratoconus affects 1 in 2000 individuals, with an incidence from 1 in 600 to 1 in 420 . The disease usually appears at puberty, progresses in $20 \%$ of cases and significantly affects the patient's quality of life. In advanced cases, complications such as myopia, irregular astigmatism, descemet membrane rupture, and corneal edema can occur leading to corneal scarring (Romero-Jimenez et al., 2010).

$\mathrm{KC}$ may be an isolated finding or it may be associated with other systemic disorders or syndromes, such as: Down syndrome, Leber congenital amaurosis and connective tissue diseases (for instance: Ehlers Danlos, Marfan syndrome, etc.). Another association that has been made was atopy.A few potential pathways may be hypothesized as cytokine dysregulation, oxidative Stress and alterations in TGF- $\beta$ regulating extracellular matrix produced by keratocytes (Soiberman et al., 2017).

The goals of treatment of Keratoconus are to provide functional visual acuity and to halt changes in the corneal shape. Intracorneal ring segments (INTACS from Addition Technology) have also been approved for the treatment of mild to moderate keratoconus in patients who are contact lens intolerant. Most patients will need spectacles and/or contact lenses postoperatively for best vision, but will have flatter corneas and easier use of lenses (Kymionis et al., 2010).

They found INTACS reduced the corneal steepening and astigmatism associated with keratoconus. There are four types of ICRS which differ in geometrical profile and diameter:
INTACS (Addition Tecnology Inc., Sunnyvlae, CA, USA), ferrara rings (Mediphacos, Belo Horizonte, Brazil), bisantis segments (Opticon 2000 SpA Soleko SpA) and Myoring (DIOPTEX) (Ertan and Colin, 2012).

The segments are made of polymethyl methacrylate and have a crescent-shaped arc length of 150 degrees. The inner diameter is $6.8 \mathrm{~mm}$ and the outer diameter is $8.1 \mathrm{~mm}$ when placed in the cornea. Intacs thickness ranges from 0.25 to 0.45 $\mathrm{mm}$ in $0.05 \mathrm{~mm}$ increments. Intacs were designed to achieve refractive adjustment by flattening the central corneal curvature while maintaining clarity in the central optic zone (Espandar and Meyer, 2010).

Specular microscopy of keratoconic corneas has revealed two populations of endothelial cells, one larger and one considerably smaller than normal.The most striking abnormality in keratoconus, however, is elongation of endothelial cells. The cells appear to have been stretched by the ectatic process with their long axis in the direction of the apex of the cone (Cingu et al., 2013).

The aim of the present study was to study the effect and safety of Femtosecond assisted implantation of INTACs on corneal endothelium using specular microscopy.

\section{PATIENTS AND METHODS}

This was a prospective comparative study conducted on 20 eyes attended the outpatient clinic of the Ophthalmology Department at Al-Azhar University Hospital (Cairo) from October 2018 to October 2029 with Keratoconus who had implantation of intracorneal ring segments (INTACS); to study the effect and safety 
of Femtosecond assisted implantation of INTACs on corneal endothelium using specular microscopy.

Inclusion criteria: Patients who were 21 years old or more, clear central cornea, contact lens intolerance, patients with progressing keratoconus and the cornea was at least $400 \mu$ thick at the insertion site for implantation of INTACS.

Exclusion criteria: Patients with existing collagen vascular, autoimmune, or immunodeficiency disease, patients who have any previous surgery as LASIK, PRK, corneal cross linking and cataract surgery, women who were pregnant or breastfeeding and patients with previous anterior segment trauma.

\section{All patients were subjected to pre- operative assessment including:}

1. Full detailed clinical, ophthalmologic examinations including best-corrected and uncorrected visual acuity (BCVA and UCVA).

2. Measurements of IOP.

3. Slit-lamp examination for anterior segment, fundus examination by $90 \mathrm{D}$ Volk lens.

4. Corneal topography by oculus Wave light Occulyzer II pentacam.

5. Endothelial cell assessment by specular microscopy using Topcon SP-1P.

\section{Details of surgical techniques:}

- Under topical anesthesia, channel creation for implantation of the ICRS was done by using a femtosecond disruptive laser $\quad(200$ KHzWaveLightFS200 Femtosecond Laser) at the steep meridian and the ring segments are inserted into the channels.

- Depth of the channel was kept at 70 $80 \%$ of maximum pachymetry in the area of ring implantation.

- The advent of the femtosecond laser has made the procedure safer with very high accuracy of implantation.

- Advantages of Femtosecond laser over conventional tunnel creation were less discomfort to patient and better patient cooperation, faster creation of tunnels, precise control of tunnel depth, width and centration, minimal tissue disturbance and faster post operative recovery.

\section{Post-operative follow-up (one month after Femtosecond assisted implantation of INTACs):}

1. Assessment of patient's post-operative uncorrected visual acuity.

2. Best corrected visual acuity.

3. Corneal topography by oculus pentacam.

4. Endothelial cell assessment by specular microscopy.

\section{Ethical considerations:}

The nature of the present study and laboratory or radiological procedures were explained to all participants. Consents were obtained from all participants. At the end of the study, all patients were informed about the results of the examinations performed and received appropriate recommendations, and treatment. Approval of ethical committee was taken before start. 


\section{Statistical Analysis:}

Data entry, processing and statistical analysis was carried out using MedCalc ver. 18.11.3 (MedCalc, Ostend, Belgium). A significant p-value was considered when it is equal or less than 0.05. Mean, Standard deviation $( \pm$ SD) and range for parametric numerical data, while Median and Inter-quartile range (IQR) for nonparametric numerical data. Frequency and percentage of non-numerical data. Wilcoxon's test was used to assess the statistical significance of the difference of a non-parametric variable between two (paired) study group means. The ROC Curve (receiver operating characteristic) provides a useful way to evaluate the Sensitivity and specificity for quantitative Diagnostic measures that categorize cases into one of two groups.

\section{RESULTS}

The mean age of all patients was 30.3 \pm 4.6 years. Regarding gender of the patients, $60 \%$ of patients were females and $40 \%$ were males (Table 1).

Table (1): Basic clinical data among 20 Keratoconus eyes

\begin{tabular}{|l|l|c|}
\hline \multicolumn{2}{|l|}{ Variables } & Frequency (\%) \\
\hline Age (years) & $30.3 \pm 4.6$ \\
\hline \multirow{2}{*}{ Gender } & Female & $12(60 \%)$ \\
\cline { 2 - 3 } & Male & $8(40 \%)$ \\
\hline
\end{tabular}

$*$ Mean \pm SD.

Regarding preoperative ophthalmic data, the mean preoperative IOP was 17.5 $\pm 2.3 \mathrm{mmHg}$, the mean preoperative UCVA was $0.17 \pm 0.1$ and the mean preoperative BCVA was $0.5 \pm 0.17$. Regarding preoperative corneal topography data, the mean preoperative spherical equivalent was $-5.94 \pm 3.2 \mathrm{D}$, the mean preoperative cylinder was $-3.5 \pm$
$1.68 \mathrm{D}$, and the mean preoperative topographic $\mathrm{K}$ values was $48.3 \pm 3.9 \mathrm{D}$. Regarding preoperative specular microscopy data, the mean preoperative endothelial cell number was $2822.5 \pm$ 321.9 , the mean preoperative coefficient of variation was $29.2 \pm 4$, and the mean preoperative percentage hexagonal cell count was $54.6 \pm 7.7$ (Table 2).

Table (1): Preoperative ophthalmic, corneal topography and specular microscopy data among 20 Keratoconus eyes

\begin{tabular}{|l|l|c|}
\hline Variables & Mean \pm SD \\
\hline \multirow{3}{*}{ Ophthalmic } & IOP (mmHg) & $17.5 \pm 2.3$ \\
& UCVA (LogMAR) & $0.17 \pm 0.1$ \\
& BCVA (LogMAR) & $0.5 \pm 0.17$ \\
\hline \multirow{2}{*}{ Corneal } & Spherical equivalent (D) & $-5.94 \pm 3.2$ \\
topography & Cylinder (D) & $-3.5 \pm 1.68$ \\
& Topographic K values (D) & $48.3 \pm 3.9$ \\
\hline \multirow{2}{*}{ Specular } & Endothelial cell number & $2822.5 \pm 321.9$ \\
microscopy & Coefficient of variation & $29.2 \pm 4$ \\
& Percentage hexagonal cell count $(\%)$ & $54.6 \pm 7.7$ \\
\hline
\end{tabular}

IOP: intra-ocular pressure. UCVA: uncorrected visual acuity. BCVA: best corrected visual acuity, D: diopter. 
Regarding postoperative ophthalmic data, the mean postoperative IOP was 18 $\pm 2 \mathrm{mmHg}$, the mean postoperative UCVA was $0.45 \pm 0.2$ and the mean postoperative BCVA was $0.77 \pm 0.18$. Regarding postoperative corneal topography data, the mean postoperative spherical equivalent was $-2.83 \pm 2.5 \mathrm{D}$, the mean postoperative cylinder was -2.19 $\pm 1.12 \mathrm{D}$, and the mean postoperative topographic $\mathrm{K}$ values was $45.37 \pm 4 \mathrm{D}$. Regarding postoperative specular microscopy data, the mean postoperative endothelial cell number was $2542.2 \pm 326$, the mean postoperative coefficient of variation was $32.26 \pm 1.9$ and the mean postoperative percentage hexagonal cell count was $46.2 \pm 3$ (Table 3 ).

Table (3): Postoperative ophthalmic, corneal topography and specular microscopy data among 20 Keratoconus eyes

\begin{tabular}{|l|l|c|}
\hline \multicolumn{2}{|c|}{ Variables } & Mean \pm SD \\
\hline \multirow{3}{*}{ Ophthalmic } & IOP (mmHg) & $18 \pm 2$ \\
& UCVA (LogMAR) & $0.45 \pm 0.2$ \\
& BCVA (LogMAR) & $0.77 \pm 0.18$ \\
\hline \multirow{2}{*}{ Corneal } & Spherical equivalent (D) & $-2.83 \pm 2.5$ \\
topography & Cylinder (D) & $-2.19 \pm 1.12$ \\
& Topographic K values (D) & $45.37 \pm 4$ \\
\hline \multirow{2}{*}{ Specular } & Endothelial cell number & $2542.2 \pm 326$ \\
microscopy & Coefficientof variation & $32.26 \pm 1.9$ \\
& Percentage hexagonal cell count $(\%)$ & $46.2 \pm 3$ \\
\hline
\end{tabular}

IOP: intra-ocular pressure. UCVA: uncorrected visual acuity. BCVA: best corrected visual acuity. D: diopter.

Comparative study between pre- and post-operative assessments revealed significant increase in post-operative UCVA and BCVA assessments in Keratoconus eyes ( $p<0.01$ respectively). Comparative study between pre- and postoperative assessments revealed; nonsignificant difference in post-operative IOP assessments in Keratoconus eyes ( $\mathrm{p}$ $>0.05$ ). This study also revealed significant increase in post-operative spherical equivalent and cylinder assessments in Keratoconus eyes ( $p<0.01$ respectively), revealed significant decrease in post-operative topographic $\mathrm{K}$ values assessments in Keratoconus eyes ( $p$ $=0.012$ ). Significant increase in postoperative coefficient of variation assessments in keratoconus eyes (p $=0.013$ ) and significant decrease in postoperative endothelial cell number and percentage hexagonal cell count assessments in keratoconus eyes ( $p<0.01$ respectively) (Table 4). 
Table (4): Comparison between keratoconus eyes as regards serial ophthalmic, corneal topography and specular microscopy assessments

\begin{tabular}{|l|c|c|c|}
\hline \multirow{2}{*}{ Variables } & $\begin{array}{c}\text { Pre-operative } \\
\text { assessment }\end{array}$ & $\begin{array}{c}\text { Post-operative } \\
\text { assessment }\end{array}$ & $\begin{array}{c}\text { Wilcoxon's } \\
\text { test }\end{array}$ \\
\cline { 2 - 4 } & Median (IQR) & Median (IQR) & P value \\
\hline Ophthalmic: & $18(16-19)$ & $18(16.5-20)$ & $=0.4683$ \\
IOP (mmHg) & $0.17(0.11-0.24)$ & $0.48(0.27-0.59)$ & $=0.0001^{* *}$ \\
UCVA (LogMAR) & $0.5(0.35-0.61)$ & $0.84(0.6-0.9)$ & $=0.0002^{* *}$ \\
BCVA (LogMAR) & & & \\
\hline Corneal topography: & $-5.86(-7.47$ to-3.83) & $-2.39(-4.37$ to-..1.2) & $=0.0032^{* *}$ \\
Spherical equivalent (D) & $-3.56(-4.67$ to-2.34) & $-2.19(-3.15$ to -1.25$)$ & $=0.0083^{* *}$ \\
Cylinder(D) & $48.68(45.6-51.7)$ & $45.37(42-48.7)$ & $=0.012^{*}$ \\
Topographic K values (D) & 2862.5 & 2520.5 & $=0.0073^{* *}$ \\
\hline Specular microscopy: & $(2535.5-3078)$ & $(2249.5-2796.5)$ & $=0.013^{*}$ \\
Endothelial cell number & $28.3(26.3-31.5)$ & $31.7(31.1-33.3)$ & $<0.0001^{* *}$ \\
Coefficient of variation & $52.6(48.4-60)$ & $46.2(44.5-48.2)$ & \\
Percentage hexagonal & & & \\
cell count (\%) & & & \\
\hline
\end{tabular}

IQR: inter-quartile range

By using ROC-curve analysis, femtosecond assisted implantation of INTACs predicted endothelial cell number improvement, with fair (72\%) accuracy, sensitivity $=40 \%$ and specificity $=95 \%(\mathrm{p}$ $<0.01$ ). By using ROC-curve analysis, Femtosecond assisted implantation of INTACs predicted coefficient of variation improvement, with fair (77\%) accuracy, sensitivity $=90 \%$ and specificity $=65 \%(\mathrm{p}$ $<0.01$ ). By using ROC-curve analysis, Femtosecond assisted implantation of INTACs predicted percentage hexagonal cell count improvement, with good $(83 \%)$ accuracy, $\quad$ sensitivity $=90 \%$ and specificity $=70 \%(\mathrm{p}<0.01)($ Table 5 and Figures 1, 2, 3).

Table (5): Roc-curve of Femtosecond assisted implantation of INTACs to predict specular microscopy parameters' improvement

\begin{tabular}{|l|c|c|c|c|c|c|}
\hline Variable & AUC & SE & $\begin{array}{c}\text { Best Cut off point } \\
\text { (Criterion) }\end{array}$ & $\begin{array}{c}\text { Sensitivity } \\
(\boldsymbol{\%})\end{array}$ & $\begin{array}{c}\text { Specificity } \\
(\%)\end{array}$ & P value \\
\hline $\begin{array}{l}\text { Endothelial } \\
\text { cell number }\end{array}$ & 0.722 & 0.0812 & $\leq 2357$ & 40 & 95 & $0.0061^{* *}$ \\
\hline $\begin{array}{l}\text { Coefficient } \\
\text { of variation }\end{array}$ & 0.775 & 0.0819 & $>30.15$ & 90 & 65 & $0.0008^{* *}$ \\
\hline $\begin{array}{l}\text { Percentage } \\
\text { hexagonal } \\
\text { cell count }(\%)\end{array}$ & 0.838 & 0.0655 & $\leq 49.87$ & 90 & 70 & $<0.0001^{* *}$ \\
\hline
\end{tabular}

ROC (Receiver operating characteristic), $\mathrm{AUC}=$ Area under curve, $\mathrm{SE}=$ Standard Error. 


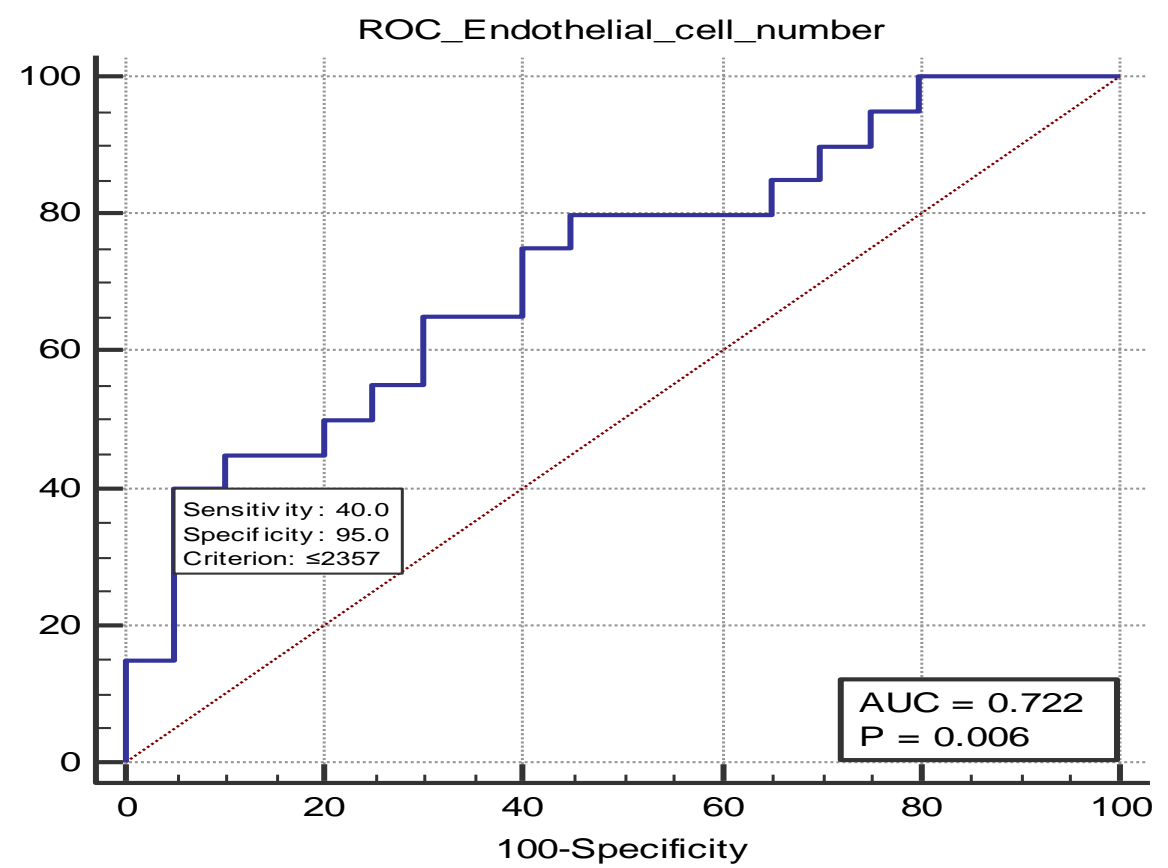

Figure (1): ROC curve of endothelial cell number improvement

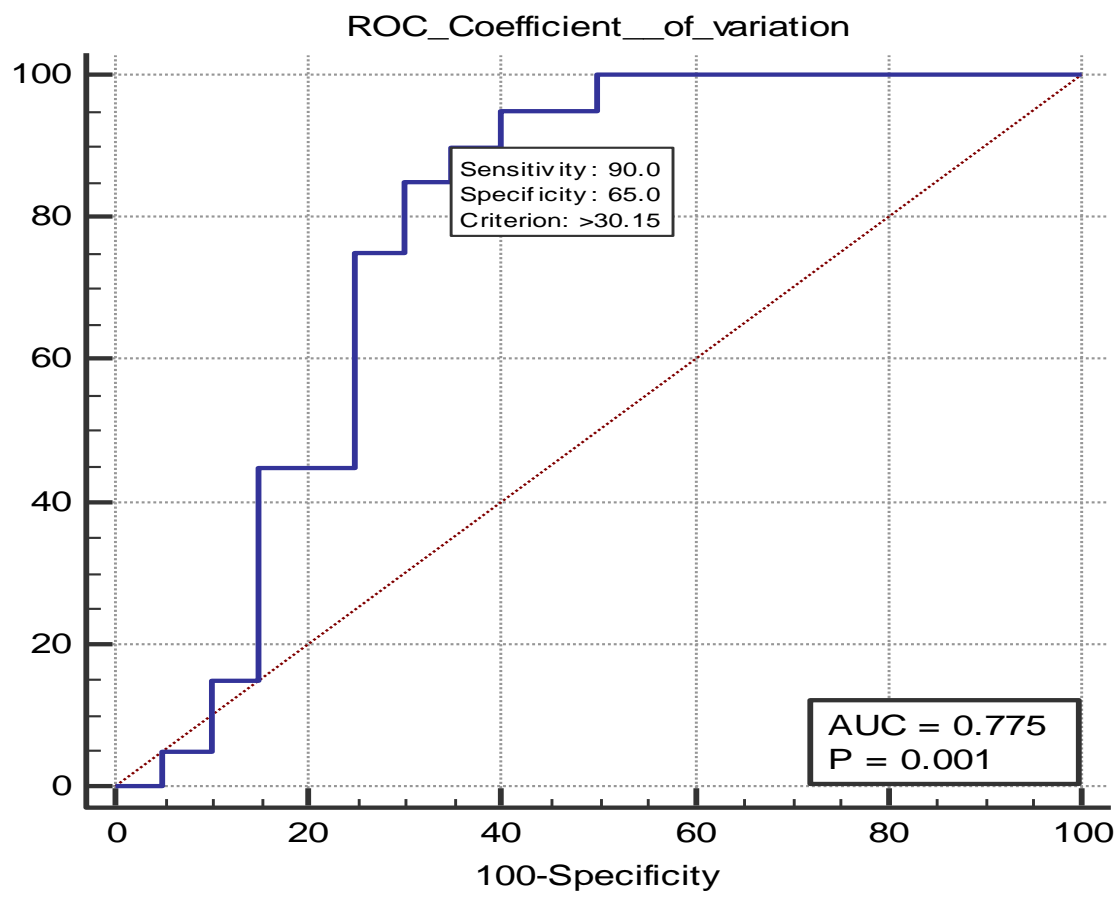

Figure (2): ROC curve of coefficient of variation improvement 


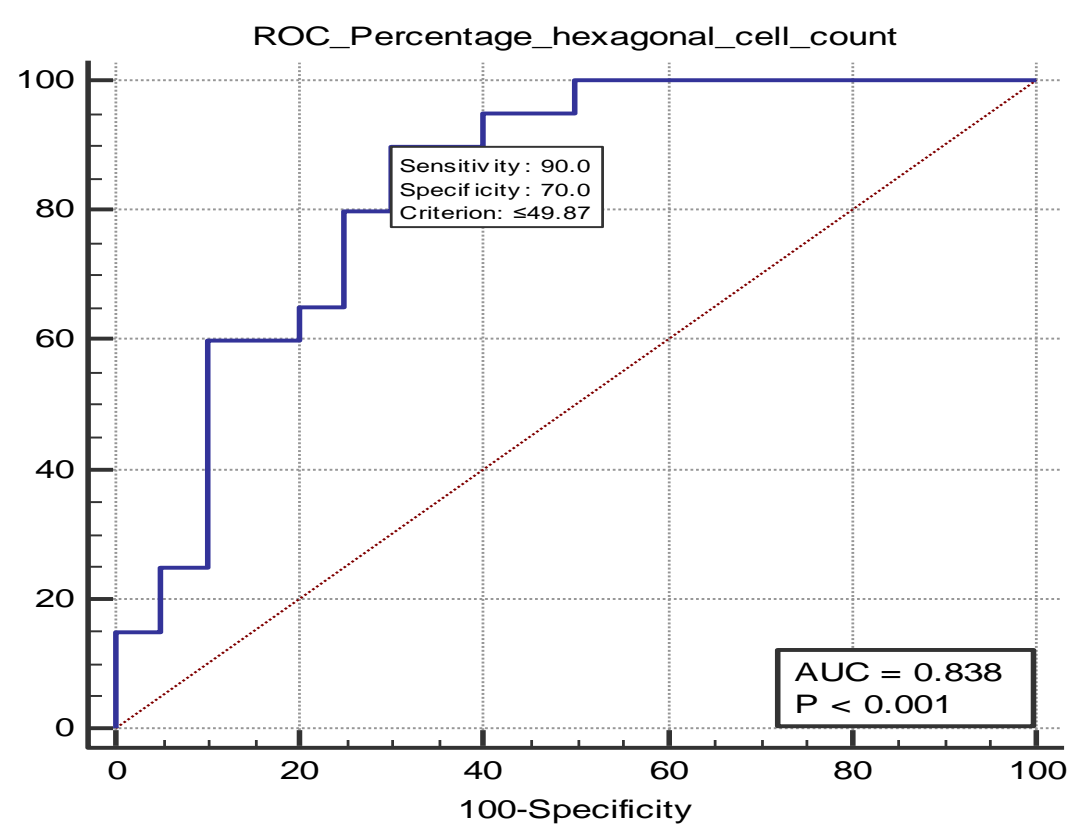

Figure (3): ROC curve of percentage hexagonal cell count improvement

\section{DISCUSSION}

This was a prospective comparative study conducted on 20 eyes with Keratoconus who have implantation of intracorneal ring segments (INTACS).

The mean age of all patients was (30.3 $\pm 4.6)$ years. Regarding gender of the patients, $60 \%$ of patients were females; while $40 \%$ were males. Thus came in agreement with Amiri et al. (2017) and Singh et al. (2020).

Regarding preoperative ophthalmic data, the mean preoperative IOP was (17.5 $\pm 2.3) \mathrm{mmHg}$, the mean preoperative UCVA was $(0.17 \pm 0.1)$ and the mean preoperative BCVA was $(0.5 \pm 0.17)$. Which came in agreement with Mohammadpour et al. (2016) reported that, a 23-year-old female was referred for decreased vision in her left eye. The uncorrected visual acuity (UCVA) was 20/120 and the best spectacle-corrected visual acuity (BCVA) was 20/80.
Regarding preoperative corneal topography data, the mean preoperative spherical equivalent was $(-5.94 \pm 3.2) \mathrm{D}$, the mean preoperative cylinder was $(-3.5$ $\pm 1.68) \mathrm{D}$, and the mean preoperative topographic $\mathrm{K}$ values was $(48.3 \pm 3.9) \mathrm{D}$. Thus came in agreement with Salustiano et al. (2013) who reported that, radial incision of $0.8 \mathrm{~mm}$ in length was made in the axis of the steepest corneal topography based on preoperative examination and the optical zone of $5.0 \mathrm{~mm}$ with a diamond knife, double-sided (Ferrara Ophthalmics, Belo Horizonte, Brazil) which was used for a cut of $80 \%$ of the caliper of that location. Thus, the ring segments were implanted in the flattest meridian to flatten the cornea in the steepest opposite meridian. Also, Monteiro et al. (2019) reported that the mean refractive cylinder was higher in the manual group preoperatively was $-3.39 \pm$ $2.04 \mathrm{D}$ versus $-2.78 \pm 1.47 \mathrm{D}, \mathrm{p}=.03$.

Regarding preoperative specular microscopy data, the mean preoperative 
endothelial cell number was $2822.5 \pm$ 321.9 , the mean preoperative coefficient of variation was $29.2 \pm 4$ and the mean preoperative percentage hexagonal cell count was 54.6 \pm 7.7. This was in agreement with Salustiano et al. (2013) who reported that, the central endothelial cell density average varied from 2652.14 \pm 299.87 to $2543.12 \pm 385.25$, and Mohammadpour et al. (2016).

Comparative study between pre- and post-operative assessments revealed significant increase in post-operative UCVA and BCVA assessments in Keratoconus eyes, which came in agreement with Mohammadpour et al. (2016) who reported that a 23-year-old female was referred for decreased vision in her left eye. Her uncorrected visual acuity (UCVA) was 20/120 and her best spectacle-corrected visual acuity (BCVA) was $20 / 80$ with $-6.00-5.75$. Ocular examinations and imaging revealed advanced progressive keratoconus. She underwent simultaneous femtosecond laser assisted Myoring implantation and accelerated intrastromal collagen crosslinking. Her UCVA and BCVA 3 months after surgery reached to 20/40 and 20/30, respectively. After 24 months, both UCVA and BSCVA improved to 20/30 and the refractive error was unremarkable (+0.37-0.12).

McLintock et al. (2020) reported that, in terms of visual outcomes, there was a significant improvement in both UDVA and CDVA. The number of eyes with 20/40 UDVA increased from $0(0 \%)$ to 10 $(71 \%)$. in $12(85.7 \%)$ of cases, the final UDVA was equal to or better than the preoperative CDVA.
Parker et al. (2015) reported that, ICRS confer a modest visual benefit: on average, 1to 2lines of BSCVA and BCVA. In particular, for AmslerKrumeich stage III or IV eyes, they show no (or markedly reduced) gains, along with more disappointed patients and elective explanation. The outcomes of ICRS placement in keratoconic eyes over 10 years. On average, eyes gained 1 line of UCVA and 2 lines of BCVA. Ten percent, however, lost at least 1 line of UCVA, and 20\% lost at least 1 line of BCVA. All eyes losing vision were Amsler-Krumeich stage III or IV.

Salman (2013) reported that one year after trans epithelial CXL, the mean improvement in the UDVA was $0.27 \mathrm{log}$ MAR, which was statistically significant. All eyes achieved a UDVA of 20/200 or better, and 59.09\% had a 1-line improvement in UDVA.

Regarding serial corneal topography assessments, comparative study between pre- and post-operative assessments revealed significant increase in postoperative spherical equivalent and cylinder assessments in Keratoconus eyes. This came in agreement with McLintock et al. (2020) who reported that, the regression equation of $0.9912 x-0.7605$ shows a good degree of accuracy with overall outcomes of phakic IOL implantation alone (following previous ICRS implantation). There was a significant improvement in UDVA, spherical equivalent and refractive cylinder.

Comparative study between pre- and post-operative assessments revealed significant decrease in post-operative endothelial cell number and percentage 
hexagonal cell count assessments in Keratoconus eyes. This came in agreement with McLintock et al. (2020) who reported that no eyes lost 2 or more lines of CDVA. There were no intraoperative or post-operative complications. The mean endothelial cell density reduced from 2399 cells $/ \mathrm{mm} 2$ to 2295 cells/mm2, a reduction of $4.3 \%$ after a mean follow-up period of 11.9 months. Salustiano et al. (2013) reported that, when comparing the number of cells between the initial and final SM examinations, a decrease was apparent between the average final cell counts in relation to the average of initial cell count; this decrease was highly significant.

By using ROC-curve analysis, femtosecond assisted implantation of INTACs predicted percentage hexagonal cell count improvement, with $83 \%$ accuracy, $90 \%$ sensitivity and $70 \%$ specificity. This was in agreement with Salustiano et al. (2013) reported that, when we compared the percentage of hexagonal cells in the initial and final exams related to the thickness and quantity of rings implanted, we found a decrease in the percentage of hexagonal cells. However, the eyes that received only two rings of thickness equal to $250 \mu$ showed a highly significant decrease compared to the percentage of hexagonal cells (9.7).

\section{CONCLUSION}

The intrastromal ring was a stent designed to alter the corneal curvature and reduce refractive errors resulting from irregularities of corneal ectasia. The ring may improve the effect of optical correction with glasses or contact lenses.

\section{REFERENCES}

1. Amiri MA, Hashemi H, Ramin S, Yekta A, Taheri A, Nabovati $P$ and Khabazkhoob M. (2017): Corneal thickness measurements with Scheimpflug and slit scanning imaging techniques in keratoconus. Journal of Current Ophthalmology, 29(1): 23-27.

2. Cingu AK, Cinar $Y$ and Turkcu FM. (2013): Effects of vernal and allergic conjunctivitis on severity of keratoconus. Int J Ophthalmol., 6(3): 370-4.

3. Ertan A and Colin J (2012): Intracorneal rings for keratoconus and keratectasia.J Cataract Refract Surg., 33(7):1303-1314.

4. Espandar L and Meyer J (2010): Keratoconus: Overview and Update on Treatment Middle East Afr J Ophthalmol., 17(1): 15-20.

5. Kymionis GD, Bouzoukis DI, Portaliou DM and Pallikaris IG. (2010): New INTACS SK implantation in patients with postlaser in situ keratomileusis corneal ectasia. Cornea, 29: 214-216.

6. McLintock CA, McKelvie J, Miraflores GS, Gatzioufas Z, Elalfy $M$ and Hamada S. (2020): Outcomes of sequential intracorneal ring segment and phakic intraocular lens insertion for visual rehabilitation in keratoconus. European Journal of Ophthalmology, 38(2): 154-167.

7. Mohammadpour M, Hahemi $H$ and Jabbarvand M. (2016): Technique of simultaneous femtosecond laser assisted Myoring implantation and 
accelerated intrastromal collagen cross-linking for management of progressive keratoconus: A novel technique. Contact Lens and Anterior Eye, 39(1): 9-14.

8. Monteiro T, Alfonso JF, Freitas R, Franqueira N, Faria-Correira F, Ambrósio $R$ and Madrid-Costa $D$. (2019): Comparison of complication rates between manual and femtosecond laser-assisted techniques for intrastromal corneal ring segments implantation in keratoconus. Current Eye Research, 44(12): 1291-1298.

9. Parker JS, van Dijk K and Melles GR. (2015): Treatment options for advanced keratoconus: A review. Survey of Ophthalmology, 60(5): 459-480.

10. Romero-Jimenez M, Santodomingo $J$ and Wolffsohn JS. (2010): Keratoconus: a review. Cont Lens Anterior Eye, 33:157-166.

11. Salman AG. (2013): Transepithelial corneal collagen crosslinking for progressive keratoconus in a pediatric age group. Journal of Cataract and
Refractive Surgery, 39(8): 11641170.

12. Salustiano R, Avila MP, Silva DS, Rannouche RZ, Salustiano LX and Paula AC. (2013): Endothelial analysis in patients having corneal intrastromal surgery with Cornealring for correction of Keratoconus. Seminars in Ophthalmology, 28(1): 19-24.

13. Singh I, Kumar D and Singh S. (2020): Specular microscopic changes in corneal endothelium after cataract surgery in different age group. J Med Sci Clin Res., 3: 36193628.

14. Soiberman U, Foster JW, Jun AS and Chakravarti S. (2017): Pathophysiology of Keratoconus: What Do We Know Today. Open Ophthalmol J., 11:252-261. 


\section{الفحص المجهري للطبقة المبطنة للقرنية بعد عملية زر اعة

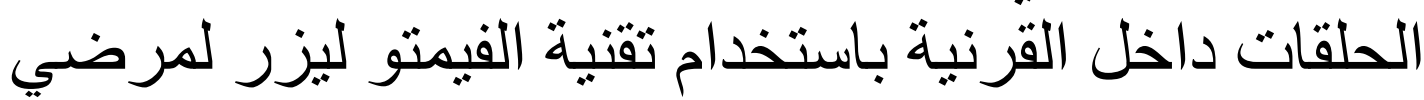

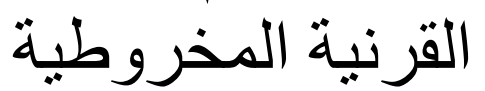

أنس علي عبد الرحيم علي, حسن عبد الوهاب علي, عبد الغني إبراهيم عبد الغني قسم طب وجراحة العيون, كلية الطب، جامعة الأزهر

\section{E-mail: anasali6095@gmail.com}

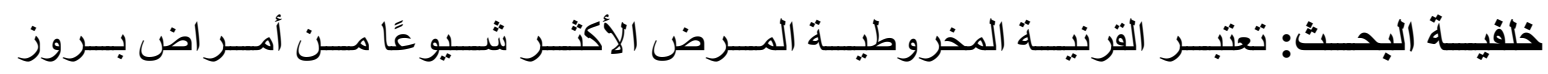

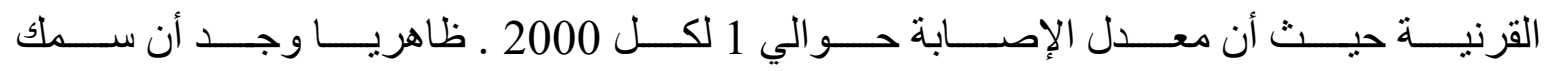

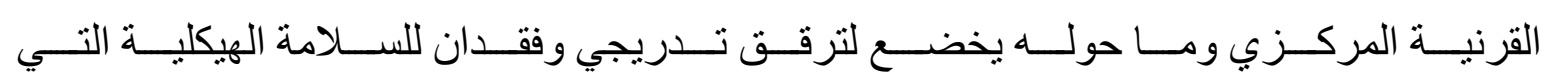

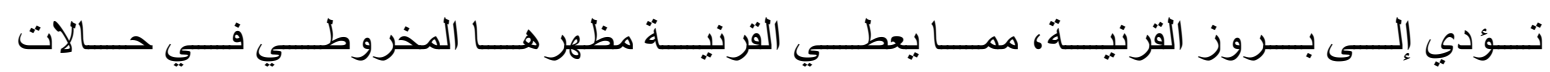

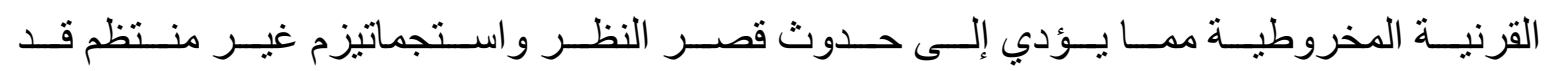

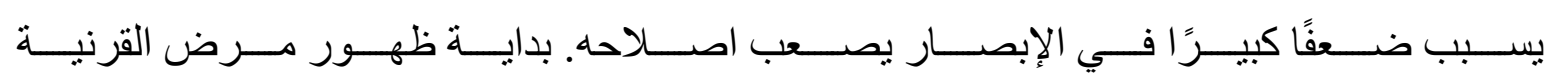

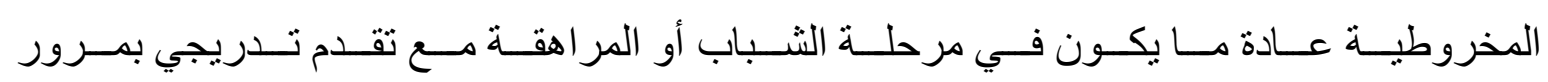

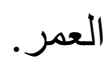

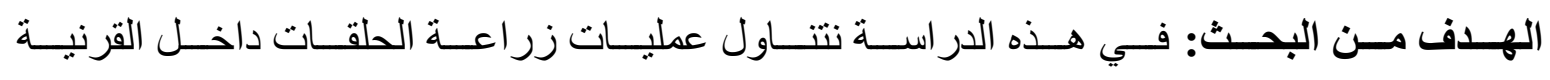

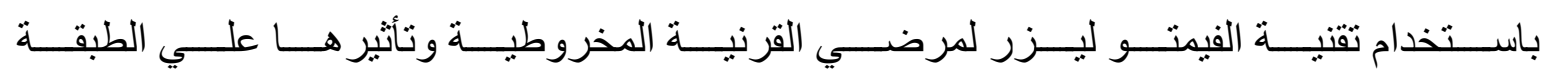
المبطنة للقرنية.

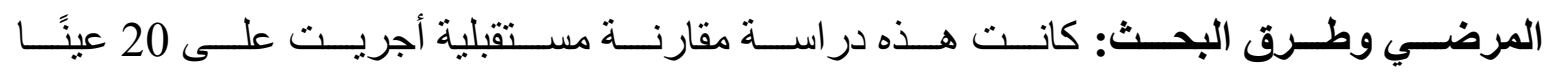

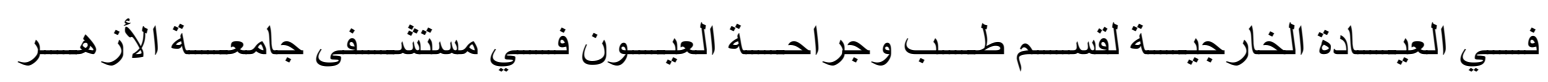

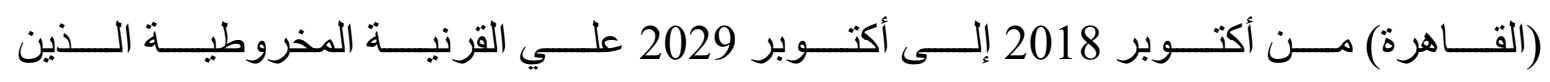
قامو ا بزر ع الحلقات داخل القرنية.

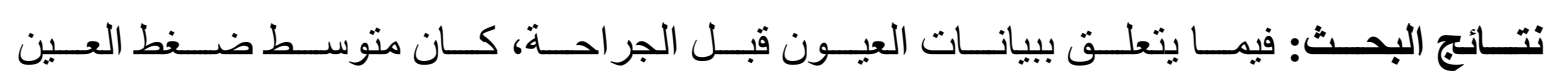

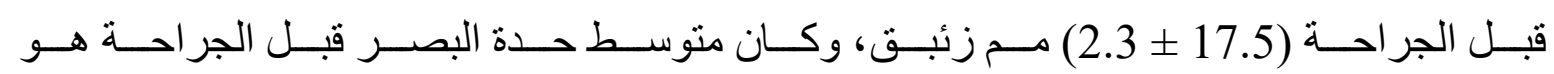

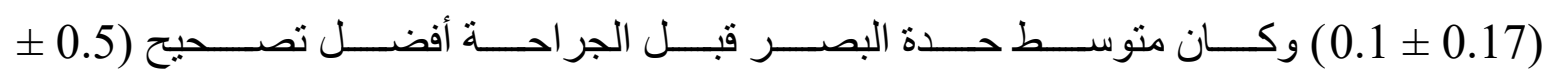

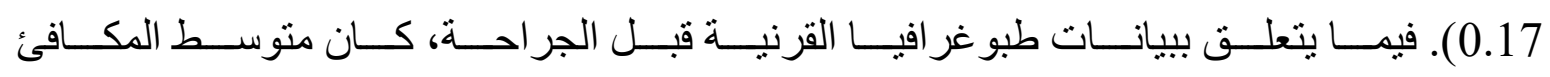

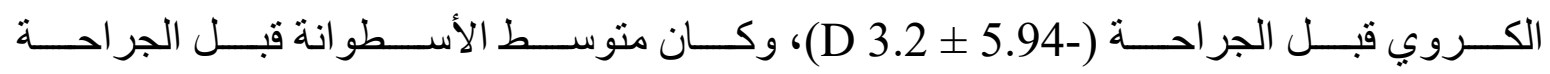




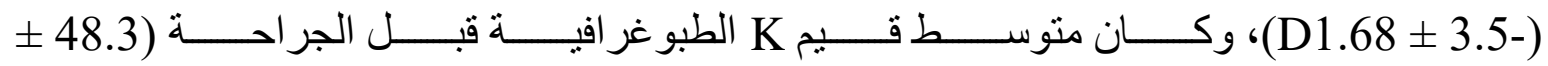

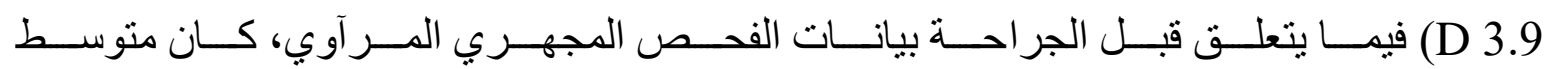

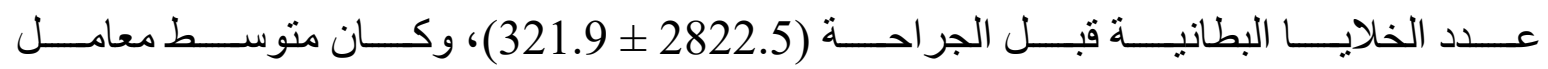

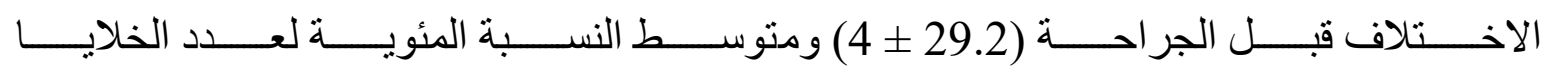

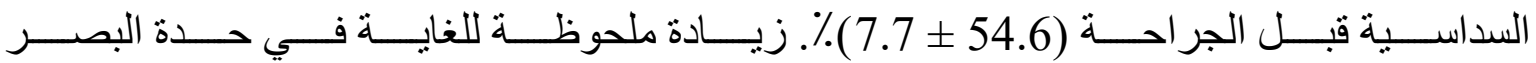

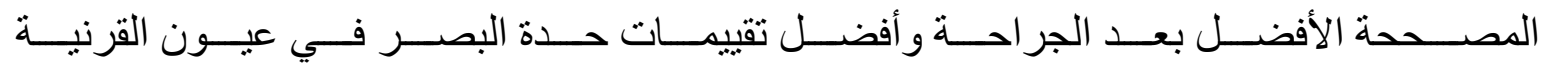

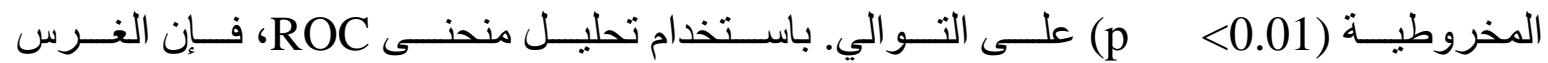

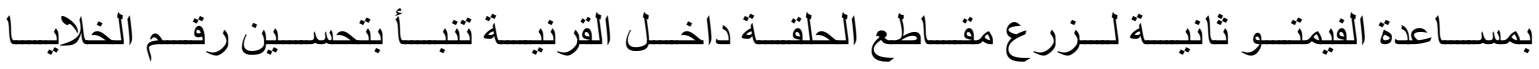

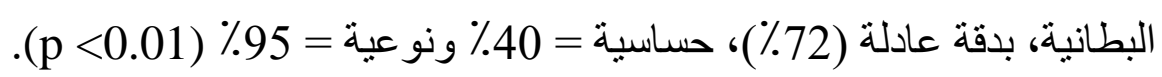

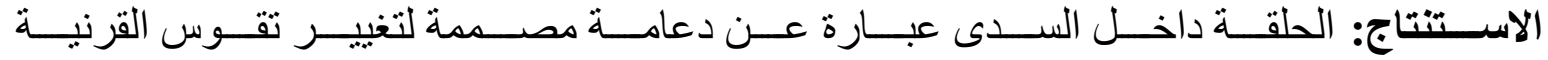

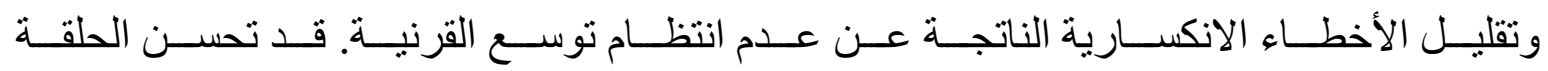
من تأثير التصحيح البصري بالنظار ات أو العدسات اللاصقة.

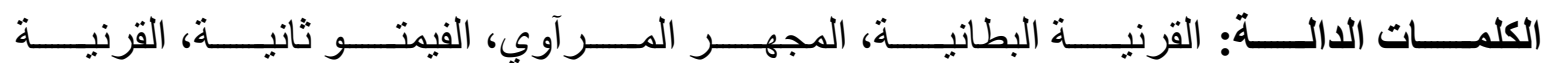
المخروطية. 